$\mathrm{Za}$

$2 \mathrm{~b} 87$

Zt09_chr_6_native

Aus $001 . \mathrm{chr}_{-}^{-} 6$ native

193.chr $\overline{6}$ native

Zt469_chron 6 native

Zt11_chr_̄ $\overline{6}$ native

$\mathrm{ZtCH} 1 \mathrm{~A} 5$ chr 6 native

Arg00.chr_6_native

KE94.chr 6 native

ZtCH1E4 chr 6 native

- CNR93.chr_6_native Zt05 chr_6_native

ISY9 2 .chr 6 native

$\frac{\text { হ }}{\stackrel{2}{+}}$

YEQ92.chr__ $\overline{6}$ native

CH95.chr_6_native

ZtCH3D7_chr_6_native

ZtCH3D1_chr_6_native

TN09.chr 6 native

UR95.chr 6 native

Zt2 89_chr_6_native

Г CRI10.chr_6_native

OregS90 chr 6 native

ZtCH3D1_chr $\overline{1} 7$

- Aus01.chr_42

- CNR93.chr 19

KE94.chr_4 4

- TN09.chr_2

TN09.chr 15

- Zt10_chr_13

YEQ92.chr_3 2

- Arg00.chr_9

- CRI10.chr-16

- OregS90.chr_6 2

- Zt09 chr 22

- ZtCHİA5_chr_192

- Aus01.chr_20 2

- CH95.chr 5

- ZtCH3D7_chr_7 2

- 193.chr 4

- ZtCH1E 4 chr 18

- Arg00.chr 16

- Zt05 chr 3

- ZtCH1̄E4_chr_9

- CNR93.chr_5

- CRI10.chr_1 3

KE94.chr 16

- UR95.chr_191

- UR95.chr_1

- Zt289 chr 52

- CH95.chr-20

- ZtCH3D1_chr_8

- Zt11 chr 20

Zt11_chr_- 41

- Zt10_chr 22

- ZtCH3D7 chr 162

193.chr 10

OregS90.chr_10 1

Zt09 chr $1 \overline{7}$

I ZtCH1A5_chr_6 1

Zt05 $\mathrm{Chr}_{-14}$

L Zt289 chr 16

[ ISY92.chr_15

ISY92.chr $\overline{6}$ 1

- YEQ92.chr_20 2

\title{
0.03
}




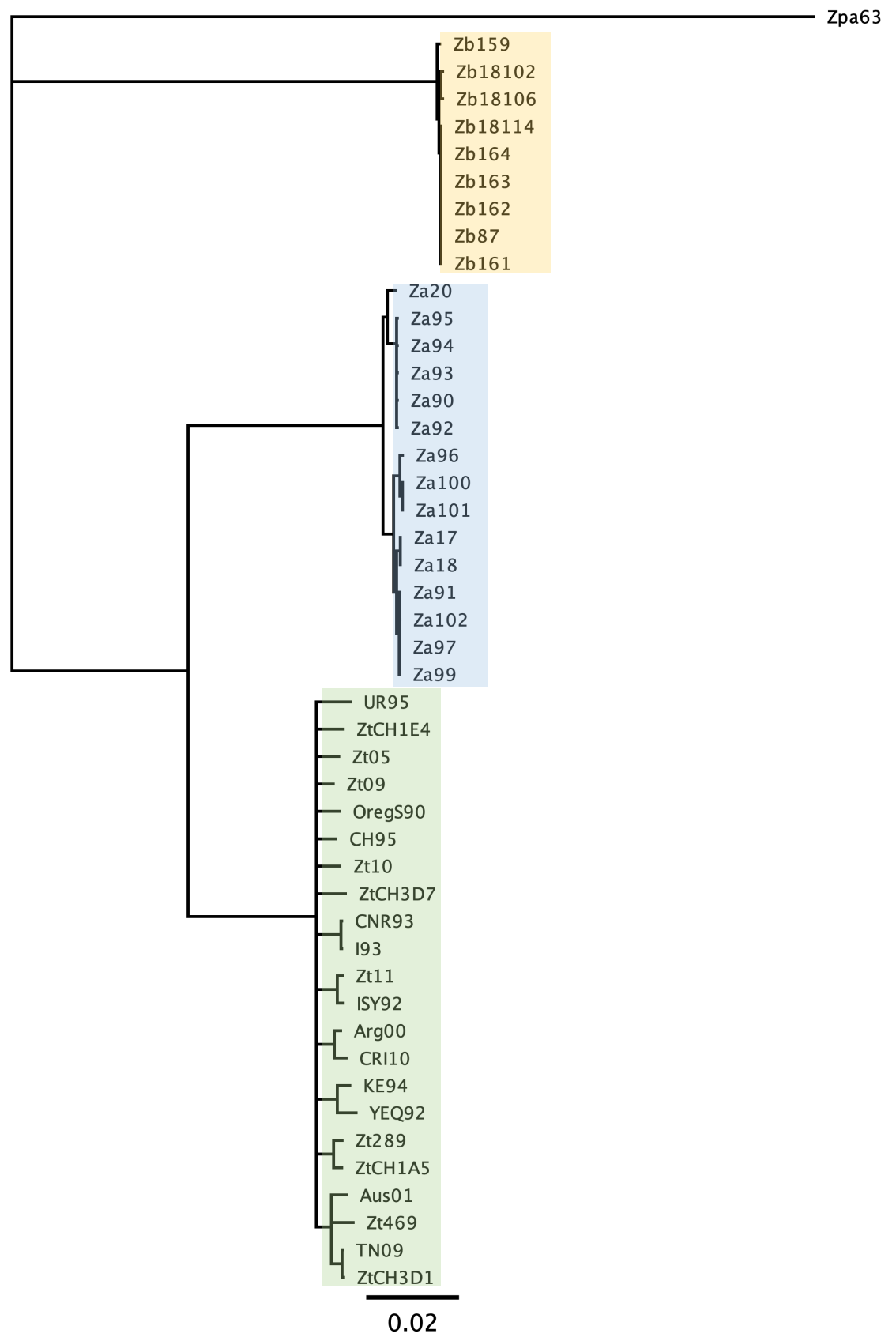




\section{C) rid}

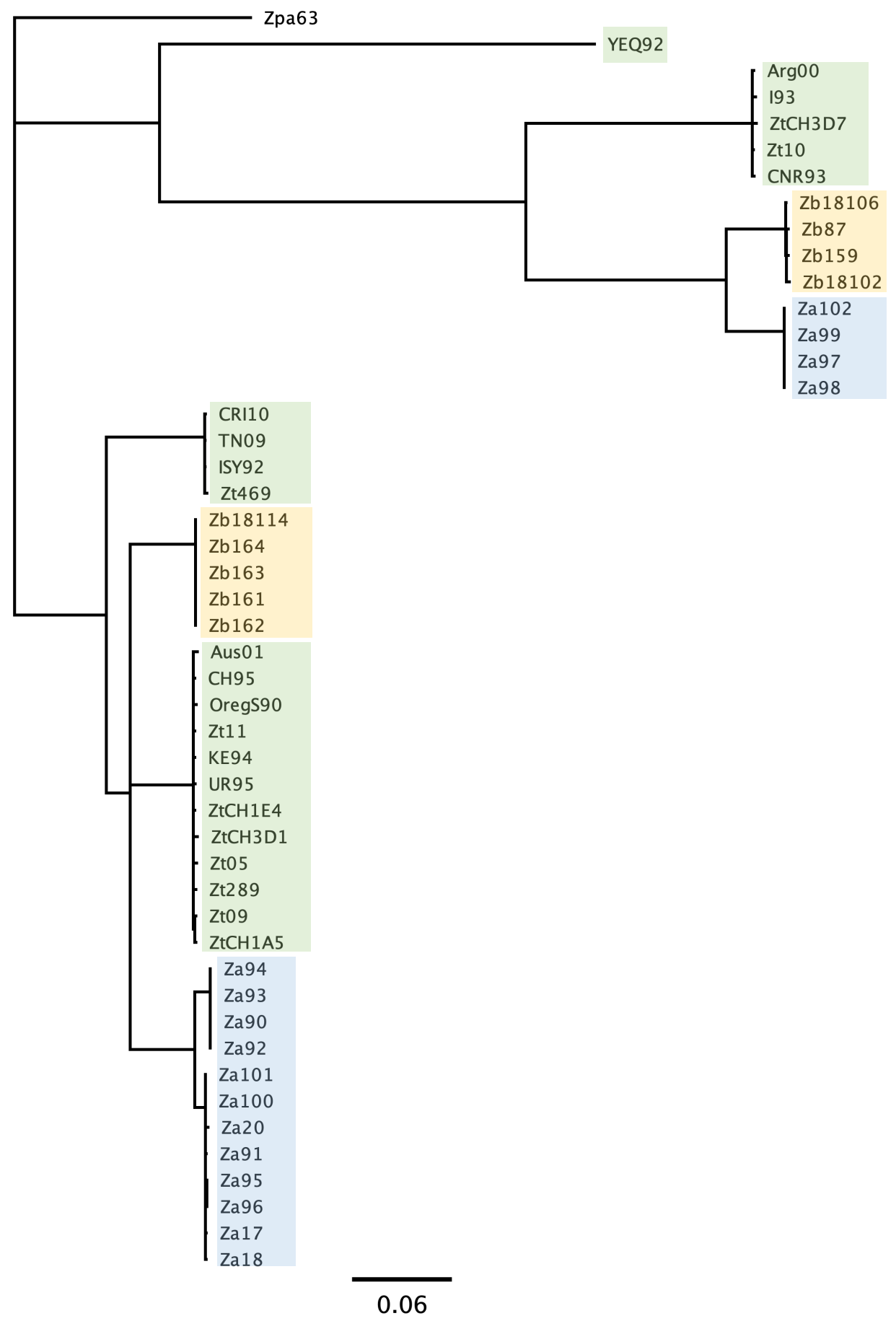

